
cell; regulatory T cell

\title{
Tumour-infiltrating inflammatory and immune cells in patients with extrahepatic cholangiocarcinoma
}

Yuki Kitano ${ }^{1}$, Hirohisa Okabe ${ }^{1}$, Yo-ichi Yamashita ${ }^{1}$, Shigeki Nakagawa ${ }^{1}$, Yoichi Saito ${ }^{2}$, Naoki Umezaki ${ }^{1}$, Masayo Tsukamoto ${ }^{1}$, Takanobu Yamao ${ }^{1}$, Kensuke Yamamura ${ }^{1}$, Kota Arima ${ }^{1}$, Takayoshi Kaida ${ }^{1}$, Tatsunori Miyata ${ }^{1}$, Kosuke Mima ${ }^{1}$, Katsunori Imai ${ }^{1}$, Daisuke Hashimoto ${ }^{1}$, Yoshihiro Komohara ${ }^{2}$, Akira Chikamoto ${ }^{1}$, Takatoshi Ishiko ${ }^{1}$ and Hideo Baba*,1

${ }^{1}$ Department of Gastroenterological Surgery, Graduate School of Medical Sciences, Kumamoto University, 1-1-1 Honjo, Chuo-ku, Kumamoto 860-8556, Japan and 2Department of Cell Pathology, Graduate School of Medical Sciences, Faculty of Life Sciences, Kumamoto University, 2-2-1 Honjo, Chuo-ku, Kumamoto 860-0811, Japan

Background: Inflammation and immune characteristics of the tumour microenvironment have therapeutic significance. The aim of this study was to investigate the clinical impact on disease progression in human extrahepatic cholangiocarcinoma (ECC).

Methods: A total of 114 consecutive ECC patients with curative resection between 2000 and 2014 were enrolled. Tumour infiltrating $\mathrm{CD} 6 \mathrm{~b}^{+}$neutrophils (TANs; tumour associated neutrophils), CD163 ${ }^{+} \mathrm{M} 2$ macrophages (TAMs; tumour associated macrophages), $\mathrm{CD}^{+} \mathrm{T}$ cells, and $\mathrm{FOXP3}^{+}$regulatory $\mathrm{T}$ cells (Tregs) were assayed by immunohistochemistry, and their relationships with patient clinicopathological characteristics and prognosis were evaluated.

Results: Tumour associated neutrophils were inversely correlated with $\mathrm{CD}^{+} \mathrm{T}$ cells $(P=0.0001)$ and positively correlated with Tregs $(P=0.001)$. High TANs $(P=0.01)$, low CD8 ${ }^{+}$T cells $(P=0.02)$, and high Tregs $(P=0.04)$ were significantly associated with poor overall survival (OS). A high-risk signature, derived from integration of intratumoural inflammatory and immune cells, was significantly associated with poor recurrence-free survival $(P=0.01)$ and $O S(P=0.0008)$. A high-risk signature was correlated with postoperative distant metastases. Furthermore, a high-risk signature was related to the resistance to gemcitabine-based chemotherapy used after recurrence.

Conclusions: Our data showed that tumour infiltrating inflammatory and immune cells may play a pivotal role in ECC progression and a high-risk signature predicted poor prognosis in ECC patients.

In the tumour microenvironment, inflammatory reactions play key roles in carcinogenesis and cancer progression. The initiation of solid tumours is thought to be governed by genetic and epigenetic alterations of neoplastic cells during a multi-step tumour pathogenesis (Hanahan and Weinberg, 2011). In the past two decades, the tumour microenvironment has also emerged as an equally important determinant of tumour behaviour (Joyce and
Pollard, 2009; McAllister and Weinberg, 2014). Inflammatory reactions, which are important for wound repair, are also associated with stimulation of cancer cell proliferation, invasion, migration, metastasis, and tumour angiogenesis (Balkwill and Mantovani, 2001; Coussens and Werb, 2002; Grivennikov et al, 2010). In addition to the cancer cells and their surrounding stroma, the tumour microenvironment includes cells associated with both

*Correspondence: Professor H Baba; E-mail: hdobaba@kumamoto-u.ac.jp

Received 26 March 2017; revised 5 October 2017; accepted 12 October 2017; published online 9 November 2017

C) 2018 Cancer Research UK. All rights reserved 0007 - 0920/18 
innate and adaptive immunity (de Visser et al, 2006). Intercellular communication controls and regulates tumour growth by direct contact or indirect interaction by autocrine and paracrine signalling of cytokines and chemokines (Grivennikov et al, 2010). Interest in targeting immune cells has increased not only in melanoma but also in gastrointestinal tumours including cholangiocarcinoma (Sabbatino et al, 2016; Fontugne et al, 2017).

Infiltration of inflammatory and immune cells such as neutrophils and macrophages that participate in defense against injury and infection can also induce tumour progression and metastasis, that is, as tumour associated neutrophils (TANs) and tumour associated macrophages (TAMs) (Qian and Pollard, 2010; Coffelt et al, 2016). Large numbers of tumour-infiltrating neutrophils indicate poor prognosis in patients with hepatocellular carcinoma (HCC) and renal cell carcinoma (Jensen et al, 2009; Li et al, 2011), as do large numbers of tumour-infiltrating macrophages in patients with HCC and Hodgkin's lymphoma (Zhu et al, 2008; Steidl et al, 2010). Moreover, previous studies revealed that TANs and TAMs are polarised toward an antitumour (N1 or M1) versus a protumour (N2 or M2) phenotype, depending on tumour microenvironment (Fridlender et al, 2009; Qian and Pollard, 2010). Regulatory T cells (Tregs) have also been shown to support tumour growth and invasion by suppressing host immune responses (Plitas and Rudensky, 2016; Tanaka and Sakaguchi, 2017). Large numbers of tumour-infiltrating Tregs have been associated with poor prognosis in patients with pancreatic and ovarian cancer (Curiel et al, 2004; Hiraoka et al, 2006). On the other hand, large numbers of tumour-infiltrating $\mathrm{CD}^{+} \mathrm{T}$ cells indicate a favourable prognosis in patients with colorectal and ovarian cancer (Naito et al, 1998; Zhang et al, 2003). Systematic analysis of tumourinfiltrating inflammatory and immune cells in cancer tissue would thus enable us to understand their role in tumour progression.

Extrahepatic cholangiocarcinoma, including perihilar and distal cholangiocarcinoma, is one of the most unfavourable cancer diagnoses because of its aggressive growth, early metastasis, and no effective treatment other than complete resection (Nakeeb et al, 1996; Takahashi et al, 2015). Although surgical techniques, perioperative management, and postoperative treatments have advanced, oncological outcomes remain unsatisfactory, even after curative resection, presumably because of lack of both effective additional treatment and predictive biomarkers of treatment response (Takahashi et al, 2015; Kobayashi et al, 2010). Pathological characteristics of human cholangiocarcinoma include infiltrating inflammatory and immune cells that participate in tumour development. Tumour-infiltrating cells do have a prognostic value in patients with biliary tract cancer (Oshikiri et al, 2003; Hasita et al, 2010; Gu et al, 2012; Goeppert et al, 2013), but it is challenging to link tumour biology and tumour inflammatory and immune cell status to treatment strategy.

The aim of this study was to investigate the role of tumourinfiltrating inflammatory and immune cells in patients with ECC. We found that a risk signature based on inflammatory and immune cell status was significantly relevant to disease progression.

\section{MATERIALS AND METHODS}

Patients. We retrospectively analysed 114 ECC patients with macroscopically complete resection (R0-1) at Kumamoto University Hospital between April 2005 and December 2014. All clinical data of patients were prospectively collected in the database of our department. Blood samples were obtained preoperatively. Patients were excluded if they died of postoperative complication within 30 days after surgery or R2 resection was performed. Ampullary carcinoma, gallbladder carcinoma, and intrahepatic cholangiocarcinoma were excluded from this study. Paraffinembedded sections were evaluated by immunohistochemistry. Pathological findings were prospectively evaluated following the Japanese classification of biliary tract cancers (Miyazaki et al, 2015). The TNM classifications were reclassified following the American Joint Committee on Cancer system, seventh edition (Edge et al, 2010). After initial surgery for the primary site, the patients were followed at 3- to 6-month intervals by clinical examinations and enhanced computed tomography (CT). Recurrence-free survival (RFS) was defined as the time between surgery and recurrence or death. Overall survival (OS) was defined as the time between surgery and death. Written informed consent was obtained from each patient, and the study procedures were approved by the Institutional Review Board.

Immunohistochemistry and evaluation. For CD66b (1:300 dilution; clone G10F5, BD Pharmigen, San Diego, CA, USA) and CD163 (1:300 dilution; clone 10D6; Novocastra, Newcastle, UK) staining, the protocol was previously shown (Komohara et al, 2008; Okabe et al, 2012). Paraffin-embedded tumour sections were dewaxed in xylene and ethanol, and autoclaved for $15 \mathrm{~min}$ in an antigen retrieval solution to retrieve their antigen epitopes; endogenous peroxidase activity was blocked by $3 \%$ hydrogen peroxide. Tissue sections were incubated overnight at $4{ }^{\circ} \mathrm{C}$ with primary antibodies, including rabbit polyclonal anti-CD8 (1:200 dilution; ab4055; Abcam, Cambridge, UK) and anti-FOXP3 (1:200 dilution; ab54501; Abcam, Cambridge, UK). The secondary antibody was incubated with horseradish peroxidase-labelled polymer (EnVision1kit; Dako, Carpinteria, CA, USA) for $30 \mathrm{~min}$ at $25^{\circ} \mathrm{C}$ and incubated in 3,30-diaminobenzidine tetrahydrochloride (applied as a $0.02 \%$ solution containing $0.005 \% \mathrm{H}_{2} \mathrm{O}_{2}$ in $0.05 \mathrm{M}$ Tris- $\mathrm{HCl} ; \mathrm{pH} 7.6)$ at $25^{\circ} \mathrm{Cfor} 5-15 \mathrm{~min}$ and counterstained with haematoxylin. Stained slides were evaluated by light microscopy at $\times 200$ by two researchers (YK and YS) blinded to patients' clinicopathological data. For CD66b, CD163, CD8, and FOXP3 staining, serial sections from tumour blocks that contained the largest amount of tumour in each patient were evaluated and positive cells in each 1-mm-diameter field were counted at three fields, which contained a large amount of cancer cells and expressed as the mean (cells per field) of triplicate counts $(\mathrm{Li}$ et al, 2011).

Prognostic prediction. Prognostic prediction was estimated based on the cell count of TAN, TAM, CD8 ${ }^{+} \mathrm{T}$-cells, and Treg by immunohistochemistry. We determined optimal cut-off quartiles that fit the current outcome for prognostic analyses of single cells. The lowest quartiles of the continuous values of CD66b, CD163, and FOXP3, and the highest quartile of that of CD8 were determined as cut-offs (Supplementary Table S1). For instance, high CD66b stands for the number of cell superior or equal to the cut-off value of 9 . Tumour associated neutrophil, TAM, and Treg were regarded as cells downregulating immune response to cancer cell, and $\mathrm{CD} 8{ }^{+} \mathrm{T}$ cells as cells upregulating immune response. The risk signature model was estimated by combining expression pattern of these cells by using Nearest Template Prediction (NTP) algorithm in which a prediction of high- and low risk is made as implemented in the NTP module of the GenePattern (http:// software.broadinstitute.org/cancer/software/genepattern/) analysis toolkit. Raw data shown in Supplementary Table S2 were put in the algorithm. Approach of the analysis with NTP was previously described (Hoshida et al, 2008; Nakagawa et al, 2016).

The predictive score was calculated by following scores of which cutoff values were already determined in single-cell analysis (Supplementary Table S1): (1) high CD66b, CD163, and FOXP3 defined as 1 point; (2) low CD66b, CD163, and FOXP3 as 0 point; (3) high CD8 as 0 point, and (4) low CD8 as 1 point. The final cutoff value was defined as three points in total because of first quartile of this continuous score. 
Statistical analysis. Continuous variables were expressed as means \pm standard deviation; differences were assessed for significance using Student's $t$-test or the Mann-Whitney test. Categorical variables were evaluated using chi-square or Fisher exact tests, as appropriate. Cox proportional hazard regression analyses were performed to identify predictors of prognosis. The multivariate analysis was performed with clinicopathological factors with a $P$-value $<0.05$ in univariate analysis. RFS and OS rates were estimated by the Kaplan-Meier method, and survival curves were compared using the log-rank test. Pearson's correlation methods were performed to identify correlations for quantitative variables with normal distributions. $P<0.05$ was considered significant. All tests were performed on JMP software version 10.0.2 (SAS Institute Inc., Cary, NC, USA).

\section{RESULTS}

Expression and correlations of TANs, TAMs, $\mathrm{CD8}^{+} \mathrm{T}$ cells, and Tregs in ECC. Immune cells were found infiltrating more frequently around cancer cells than ducts of normal glands. One of those immune regulator, TAN expressing $\mathrm{CD} 6 \mathrm{~b}^{+}$, is shown in Figure 1A. Not only CD66b ${ }^{+}$cells but also $\mathrm{CD}_{163}{ }^{+}, \mathrm{CD}^{+}$, and $\mathrm{FOXP}^{+}$cells were detected in tumour stroma (Figure 1B). The distributions of positively labelled cells are shown in Figure 2A. The number of $\mathrm{CD} 6 \mathrm{~b}^{+}$cells was negatively correlated with $\mathrm{CD}^{+}$cells $(r=-0.35, P=0.0001)$ (Figures $1 \mathrm{C}$ and 2B), positively correlated with $\mathrm{FOXP}^{+}$cells $(r=0.30, P=0.001)$ (Figure 2C), and positively correlated with $\mathrm{CD} 163^{+}$cells $(r=0.24$, $P=0.009$ ) (Figure 2D). No significant correlation of $\mathrm{CD} 163^{+}$with either $\mathrm{CD}^{+}(r=0.16, P=0.08)$ or $\mathrm{FOXP}^{+}$cells $(r=0.16$, $P=0.09)$ was seen.

Prognostic value of tumour-infiltrating inflammatory and immune cells. The median patient follow-up was 62.6 months
(95\% confidence limits: 51.4-94.1), measured by reversed Kaplan-Meier. There were 72 recurrences and 69 deaths among the 114 ECC patients. The cut-off values of cell count for positivity of each cell marker are shown in Supplementary Table S1. High TANs (HR, 2.20; 95\% CI, 1.22-4.29; $P=0.01$ ) (Figure 3A), low $\mathrm{CD}^{+} \mathrm{T}$ cells (HR, 2.03; 95\% CI, 1.13-3.99; $P=0.02$ ) (Figure 3C), and high Tregs (HR, 1.78 ; 95\% CI, 1.03-3.26; $P=0.04$ ) (Figure 3D) were significantly associated with worse OS; however, high TAMs were not (HR, $1.42 ; 95 \% \mathrm{CI}, 0.84-2.53 ; P=0.21)$ (Figure 3B).

Risk signature of tumour-infiltrating inflammatory and immune cells is correlated with poor prognosis. To investigate the relationship of tumour-infiltrating inflammatory and immune cells with patient characteristics and prognosis, we constructed a risk signature model relevant to poor overall survival based on expression profiles of inflammatory and immune cells (Figure 4A). Colour red stands for high number of tumour-infiltrating cells, and blue means low number. To investigate the prognostic impact of immune profile in ECC patients, we stratified the patients into high- and low-risk groups based on the expression pattern of four immune cells with an NTP algorithm as described above. Although there were no significant differences in the background clinicopathological features of the two groups (Table 1), the high-risk signature group had significantly worse $\mathrm{RFS}(\mathrm{HR}=1.76 ; 95 \% \mathrm{CI}$ : 1.14-2.75; $P=0.01$; Supplementary Figure $\mathrm{S} 1)$ and $\mathrm{OS}(\mathrm{HR}=2.30$; 95\% CI: $1.40-3.82 ; P=0.0008$; Figure $4 \mathrm{~B}$ ) than the low-risk signature group. Moreover, to simplify this risk signature and use in further prospective study, we transposed the risk signature into a predictive score. Supplementary Figure S2a showed the survival curve of OS based on calculated score as described above. The high-score group determined by predictive score $\geqslant 3$ had significantly worse OS than the low-score group with the score $<3 \quad(\mathrm{HR}=2.81 ; 95 \% \mathrm{CI}: 1.54-5.54 ; P=0.001$; Supplementary Figure S2b). Regarding RFS, high-score group also showed worse
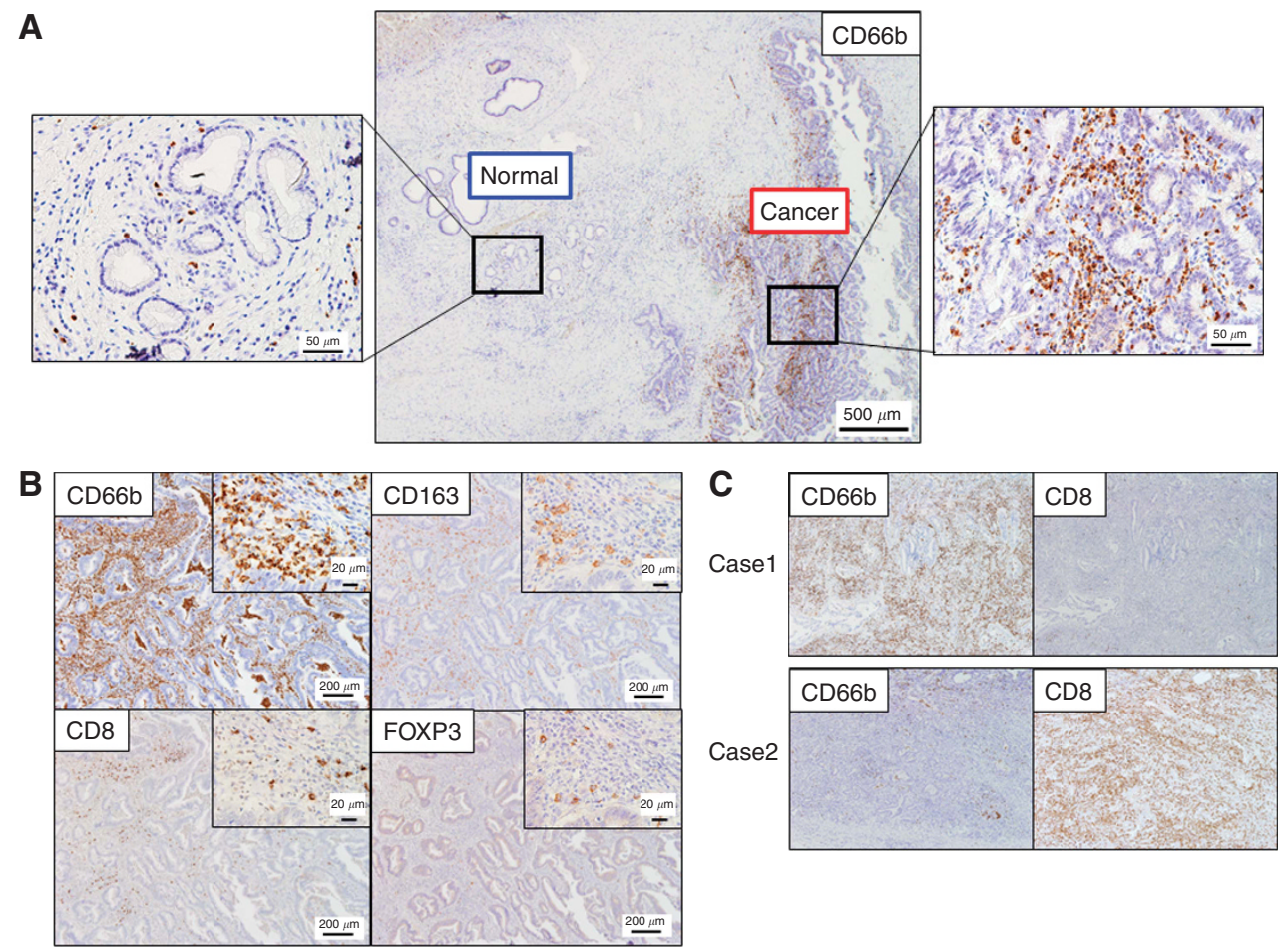

Figure 1. Immunohistochemistry on tumour-filtrating $\mathrm{CD}_{6} 6 \mathrm{~b}^{+}, \mathrm{CD}_{163}{ }^{+}, \mathrm{CD}^{+}$and $\mathrm{FOXP} 3^{+}$cells. (A) Expression of $\mathrm{CD} 66 \mathrm{~b}^{+}$cells in normal ducts and ductal cancer in patients with extrahepatic cholangiocarcinoma. (B) Representative pictures of immunohistochemical staining (CD66b, CD8, CD163 and FOXP3) with serial sections in extrahepatic cholangiocarcinoma are shown. (C) Representative cases with intratumoural exclusive expression patterns of $\mathrm{CD}_{6} 6 \mathrm{~b}^{+}$and $\mathrm{CD} 8^{+}$cells. 

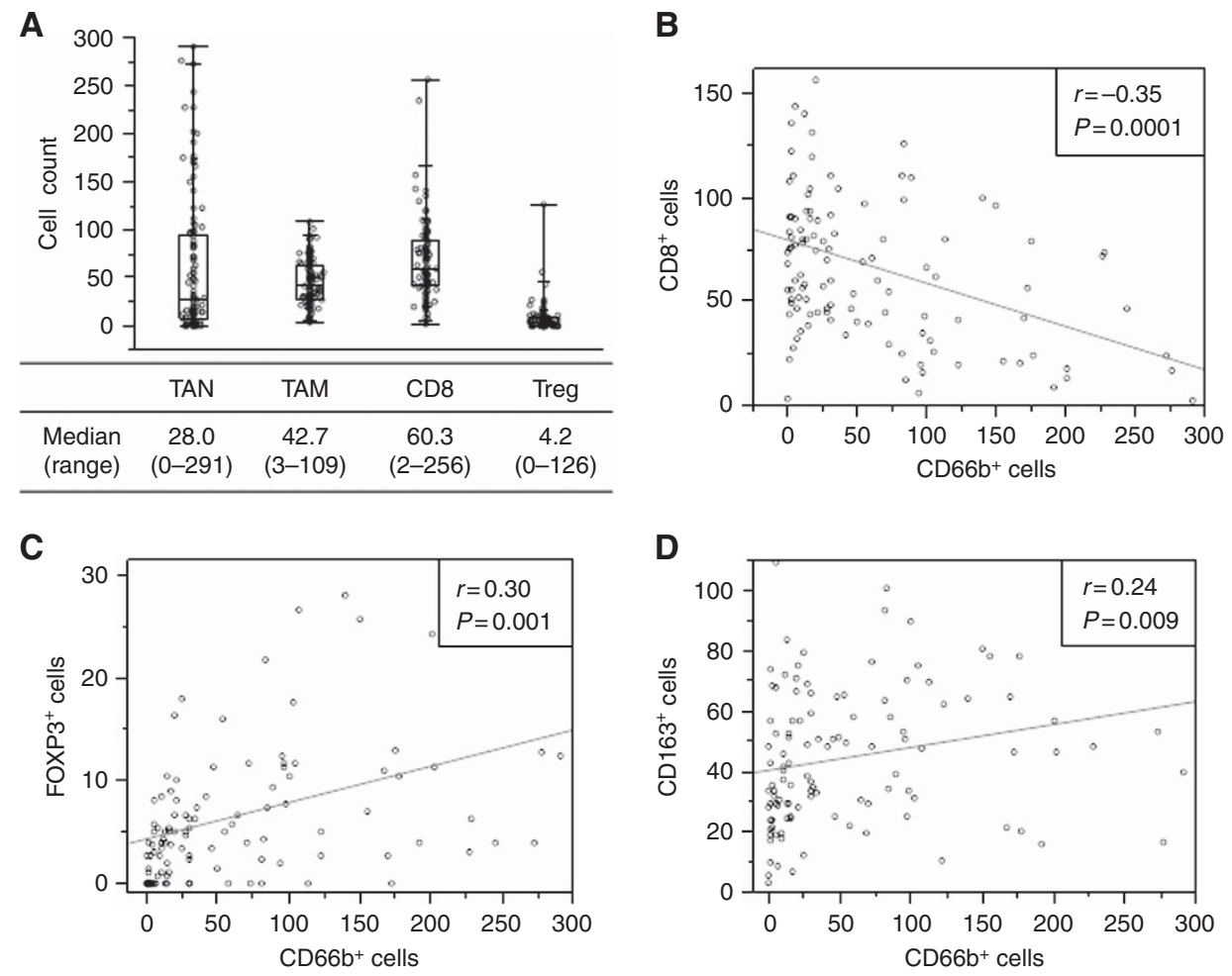

Figure 2. Distribution and relationships of tumour-infiltrating immune cells. (A) Distributions of tumour-infiltrating $C D 66 b^{+}, C D 163^{+}, C D 8^{+}$and FOXP3 ${ }^{+}$cells are shown in box plots. (B-D) The relationships of (B) $\mathrm{CD}_{6} 6 \mathrm{~b}^{+}$and CD8 ${ }^{+}$, (C) $\mathrm{CD}_{6} 6 \mathrm{~b}^{+}$and FOXP3 ${ }^{+},(\mathrm{D}) \mathrm{CD} 66 \mathrm{~b}^{+}$and $\mathrm{CD} 163^{+}$ expression are shown. One circle corresponds to one patient. TAM = tumour associated macrophage; TAN = tumour associated neutrophil; Treg $=$ regulatory $T$ cells .

A

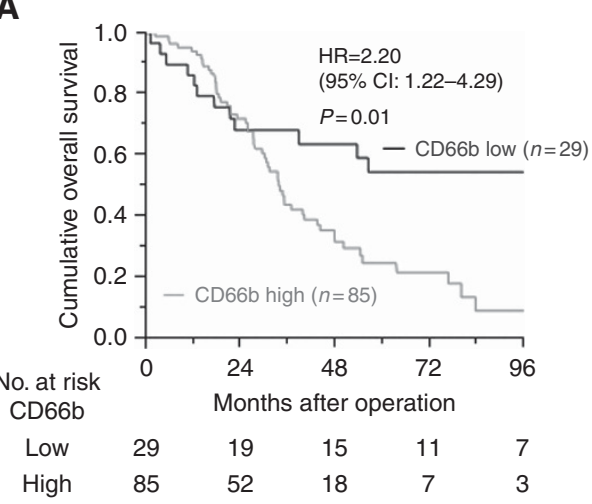

C

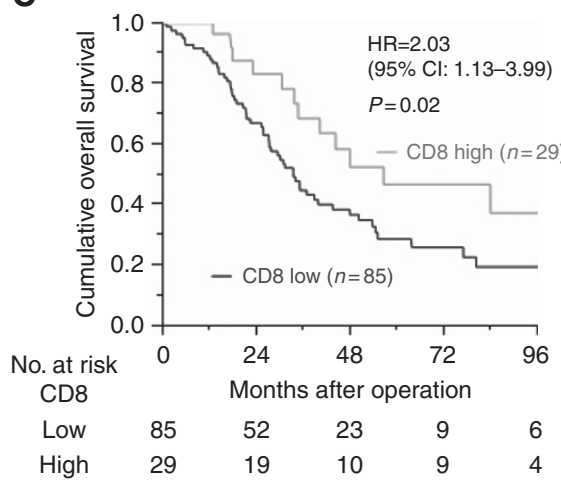

B

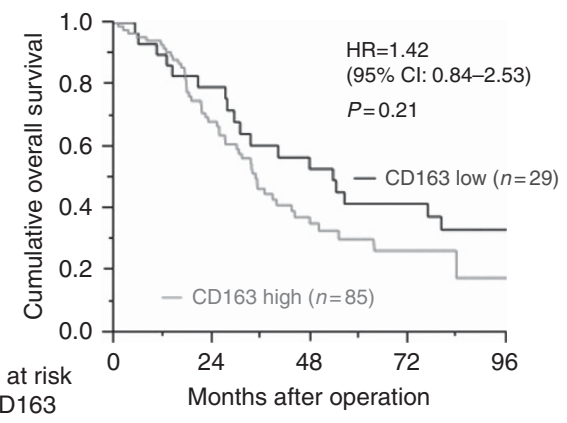

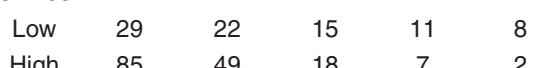

D

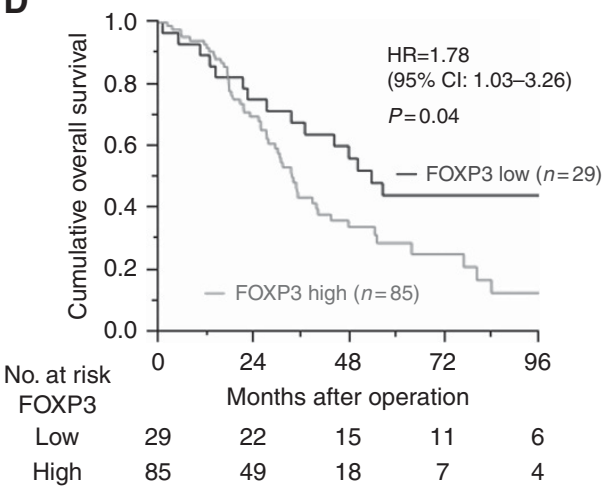

Figure 3. Overall survival and tumour-infiltrating immune cell status. Overall survival and (A) CD $66 \mathrm{~b}^{+}$cell, (B) $\mathrm{CD} 163^{+}$cell, (C) CD8 ${ }^{+}$cell and (D) $\mathrm{FOXP3}^{+}$cell status are shown. $\mathrm{Cl}=$ confidence interval; $\mathrm{HR}=$ hazard ratio. 
A

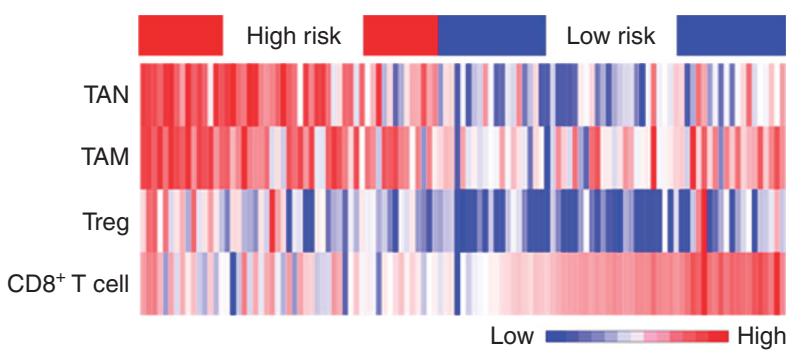

B

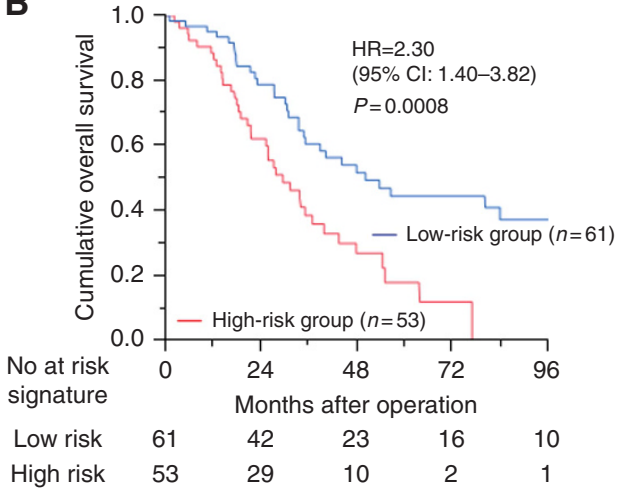

C

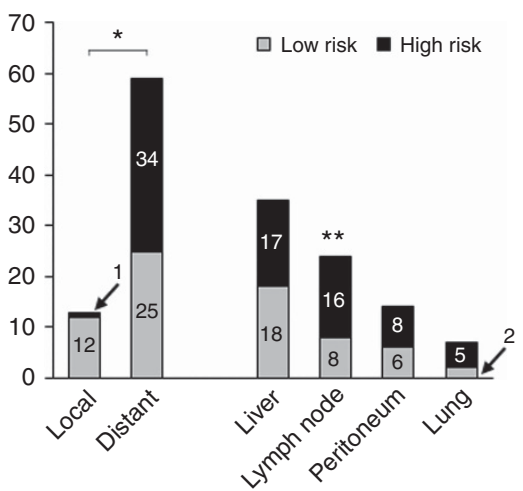

D

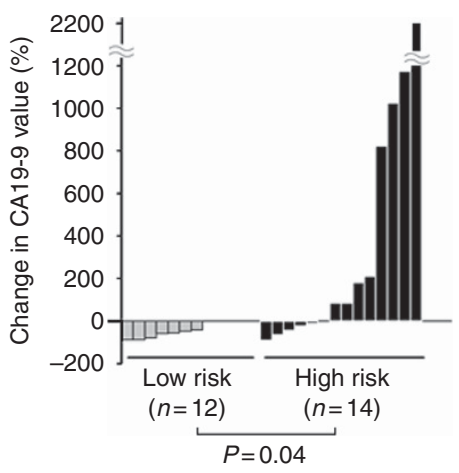

E

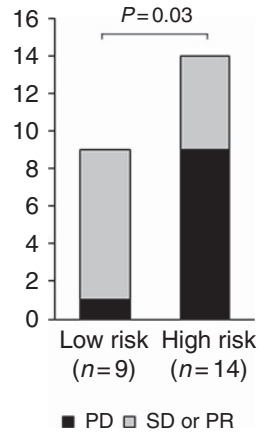

Figure 4. Risk signature model of tumour-infiltrating inflammatory and immune cells and postoperative outcome. (A) Risk signature is derived from the integration of tumour-infiltrating inflammatory and immune cell expression and shown as a heat map. (B) Overall survival based on the risk signature model of tumour-infiltrating inflammatory and immune cells is shown. (C) Comparison of recurrence sites between high- and low-risk signature. (D) Change in CA19-9 level between the initiation of gemcitabine-based chemotherapy and 3 months after the start in patients with recurrence. (E) The effect of chemotherapy on recurrent disease was assessed by RECIST criteria. Progressive disease (PD) was shown as 'not effective', whereas stable disease (SD) and partial response (PR) are shown as 'effective'. $\mathrm{Cl}=$ confidence interval; $\mathrm{HR}=$ hazard ratio; $T A M=$ tumour associated macrophage; TAN = tumour associated neutrophil; Treg $=$ regulatory $T$ cells. ${ }^{\star} P=0.005 ;{ }^{*} P=0.02$.

RFS than low-score group, although the difference did not reach statistical significance $(\mathrm{HR}=1.61 ; P=0.07$; Supplementary Figure S2c and d).

Risk signature of tumour-infiltrating inflammatory and immune cells is independently correlated with both RFS and OS. Univariate and multivariate analyses for RFS and OS were performed (Supplementary Table S3 and Table 2). Univariate analysis for RFS revealed that low albumin $\left(<3.8 \mathrm{~g} \mathrm{dl}^{-1}\right)$, high CA19-9 $\left(>74 \mathrm{U} \mathrm{ml}^{-1}\right)$, large tumour size $(>25 \mathrm{~mm})$, presence of lymph node metastasis, and high-risk signature were significantly associated with poor RFS. Multivariate analysis including those factors showed that the presence of lymph node metastasis $(\mathrm{HR}=1.94, P=0.005)$, high-risk signature $(\mathrm{HR}=1.62, P=0.04)$, and large tumour size $(\mathrm{HR}=1.60, P=0.04)$ were independent predictors of poor RFS. Univariate analysis found that high CA199 , presence of lymph node metastasis, and high-risk signature were significantly associated with poor OS. High-risk signature $(\mathrm{HR}=2.09, P=0.004)$ and presence of lymph node metastasis ( $\mathrm{HR}=1.96, P=0.009)$ were independent predictors of poor OS in multivariate analysis.

Risk signature of tumour-infiltrating inflammatory and immune cells is correlated with distant metastases and resistance to chemotherapy used after recurrence. To address why a highrisk signature was correlated with poor prognosis, recurrence patterns were carefully investigated. All patients with recurrence could be properly assessed for the analysis. Recurrences involving the hepatic portal region were defined as local; recurrences involving organs such as the liver, lymph nodes, lungs, and peritoneum were defined as distant. As regional lymph nodes were routinely removed during curative surgery, recurrence of lymph node metastases was determined as distant metastases in the current study. A high-risk signature was correlated with distant recurrence, whereas low-risk signatures were correlated with local recurrence $(P=0.0005$; Figure $4 \mathrm{C})$. Since ECC tended to be resistant to chemotherapeutic reagents, resulting in the lack of effective standard chemotherapy, the impact of risk-signature on the activity of chemotherapy used after recurrence was also investigated. Carbohydrate antigen 19-9 values at the recurrence and 3 months after the beginning of treatment were included in the comparative analysis. Complete data were available in 26 patients receiving gemcitabine-based chemotherapy regimen and patients' background is shown in Supplementary Table S4. Intriguingly, a significantly greater decrease in CA19-9 was seen in the low-risk signature group than was in the high-risk signature group $(P=0.04$; Figure 4D). Furthermore, chemotherapeutic effect evaluated by CT was confirmed by Response Evaluation Criteria in Solid Tumors v1.1 criteria. Recurrent tumour size was measurable in 23 patients, and we evaluated the chemotherapeutic effect at 3 months after an administration of chemotherapy. The number of progressive disease in the low-risk signature group $(n=1)$ was significantly less than in the high-risk signature group $(n=9)(P=0.03$, Figure $4 \mathrm{E})$. Survival rates from recurrence of high-risk signature group was worse than low-risk group, although 
Table 1. Baseline clinicopathological factors in patients with high- and low-risk signatures

Inflammation risk signature

$P$-value

\begin{tabular}{|c|c|c|c|c|}
\hline & Total $(n=114)$ & High risk $(n=53)$ & Low risk $(n=61)$ & \\
\hline Age & & & & 0.11 \\
\hline Mean \pm s.d. & $67.5 \pm 10.1$ & $69.1 \pm 8.1$ & $66.1 \pm 11.4$ & \\
\hline Sex & & & & 0.26 \\
\hline Tumour location & & & & 0.57 \\
\hline $\begin{array}{l}\text { Perihilar } \\
\text { Distal }\end{array}$ & $\begin{array}{l}57(50.0 \%) \\
57(50.0 \%)\end{array}$ & $\begin{array}{l}28(52.8 \%) \\
25(47.2 \%)\end{array}$ & $\begin{array}{l}29(47.5 \%) \\
32(52.5 \%)\end{array}$ & \\
\hline $\begin{array}{l}\text { Present } \\
\text { Absent }\end{array}$ & $\begin{array}{l}27(23.9 \%) \\
87(76.1 \%)\end{array}$ & $\begin{array}{l}11(20.8 \%) \\
42(79.2 \%)\end{array}$ & $\begin{array}{l}16(26.7 \%) \\
45(73.3 \%)\end{array}$ & \\
\hline BMI & & & & 0.56 \\
\hline Mean \pm s.d. & $23.4 \pm 3.5$ & $23.2 \pm 3.8$ & $23.6 \pm 3.1$ & \\
\hline Albumin $\left(\mathrm{g} \mathrm{dl}^{-1}\right)$ & & & & 0.57 \\
\hline Mean \pm s.d. & $0.65 \pm 1.0$ & $0.69 \pm 1.0$ & $0.62 \pm 1.0$ & \\
\hline WBC $\left(\mu \mathrm{I}^{-1}\right)$ & & & & 0.38 \\
\hline Mean \pm s.d. & $5506 \pm 1589$ & $5647 \pm 1714$ & $5384 \pm 1475$ & \\
\hline Neutrophil $\left(\left.\mu\right|^{-1}\right)$ & & & & 0.29 \\
\hline Mean \pm s.d. & $3308 \pm 1324$ & $3424 \pm 1368$ & $3153 \pm 1353$ & \\
\hline Lymphocyte $\left(\left.\mu\right|^{-1}\right)$ & & & & 0.57 \\
\hline Mean \pm s.d. & $1598 \pm 622$ & $1623 \pm 748$ & $1555 \pm 532$ & \\
\hline CEA (ng ml ${ }^{-1}$ ) & & & & 0.31 \\
\hline Mean \pm s.d. & $2.9 \pm 7.8$ & $3.7 \pm 11.0$ & $2.2 \pm 2.4$ & \\
\hline CA19-9 $\left(\mathrm{U} \mathrm{ml}^{-1}\right)$ & & & & 0.95 \\
\hline Postoperative complication ( $C D \geqslant I I l a)$ & & & & 0.11 \\
\hline $\begin{array}{l}\text { Present } \\
\text { Absent }\end{array}$ & $\begin{array}{l}65(57.0 \%) \\
49(43.0 \%)\end{array}$ & $\begin{array}{l}26(49.1 \%) \\
27(50.9 \%)\end{array}$ & $\begin{array}{l}39(63.9 \%) \\
22(36.1 \%)\end{array}$ & \\
\hline Mortality within 30 days after surgery & & & & 0.48 \\
\hline $\begin{array}{l}\text { Present } \\
\text { Absent }\end{array}$ & $\begin{array}{c}3(2.6 \%) \\
111(97.4 \%)\end{array}$ & $\begin{array}{c}2(3.8 \%) \\
51(96.2 \%)\end{array}$ & $\begin{array}{c}1(1.6 \%) \\
60(98.4 \%)\end{array}$ & \\
\hline Tumour size $(\mathrm{mm})$ & & & & 0.65 \\
\hline Mean \pm s.d. & $30 \pm 15$ & $31 \pm 16$ & $29 \pm 15$ & \\
\hline Histologic grade & & & & 0.59 \\
\hline $\begin{array}{l}\text { Papillary } \\
\text { Well } \\
\text { Moderately } \\
\text { Poorly }\end{array}$ & $\begin{array}{c}4 \text { (3.5\%) } \\
51(44.7 \%) \\
48(42.2 \%) \\
11(9.6 \%)\end{array}$ & $\begin{array}{c}2 \text { (3.8\%) } \\
24(45.3 \%) \\
24(45.3 \%) \\
3(5.7 \%)\end{array}$ & $\begin{array}{c}2 \text { (3.3\%) } \\
27(44.3 \%) \\
24(39.3 \%) \\
8(13.1 \%)\end{array}$ & \\
\hline pT & & & & 0.74 \\
\hline $\begin{array}{l}\text { T1 } \\
\text { T2 } \\
\text { T3 } \\
\text { T4 }\end{array}$ & $\begin{array}{c}8 \text { (7.0\%) } \\
52 \text { (45.6\%) } \\
50 \text { (43.9\%) } \\
4(3.5 \%)\end{array}$ & $\begin{array}{c}3(5.7 \%) \\
24(45.3 \%) \\
25(47.2 .1 \%) \\
1(1.9 \%)\end{array}$ & $\begin{array}{c}5 \text { (8.2\%) } \\
28(45.9 \%) \\
25(41.0 \%) \\
3(4.9 \%)\end{array}$ & \\
\hline $\mathrm{pN}$ & & & & 0.87 \\
\hline $\begin{array}{l}\text { No } \\
\text { N1 }\end{array}$ & $\begin{array}{l}74 \text { (64.9\%) } \\
40 \text { (35.1\%) }\end{array}$ & $\begin{array}{l}34 \text { (64.2\%) } \\
19(35.8 \%)\end{array}$ & $\begin{array}{l}40(65.6 \%) \\
21(34.4 \%)\end{array}$ & \\
\hline
\end{tabular}


Table 1. (Continued)

\begin{tabular}{|c|c|c|c|c|}
\hline & & \multicolumn{2}{|c|}{ Inflammation risk signature } & $P$-value \\
\hline Residual tumour & & & & 0.48 \\
\hline Adjuvant therapy & & & & 0.79 \\
\hline Present & $51(44.7 \%)$ & $23(43.4 \%)$ & $28(45.9 \%)$ & \\
\hline
\end{tabular}

Table 2. Univariate and multivariate analysis for overall survival

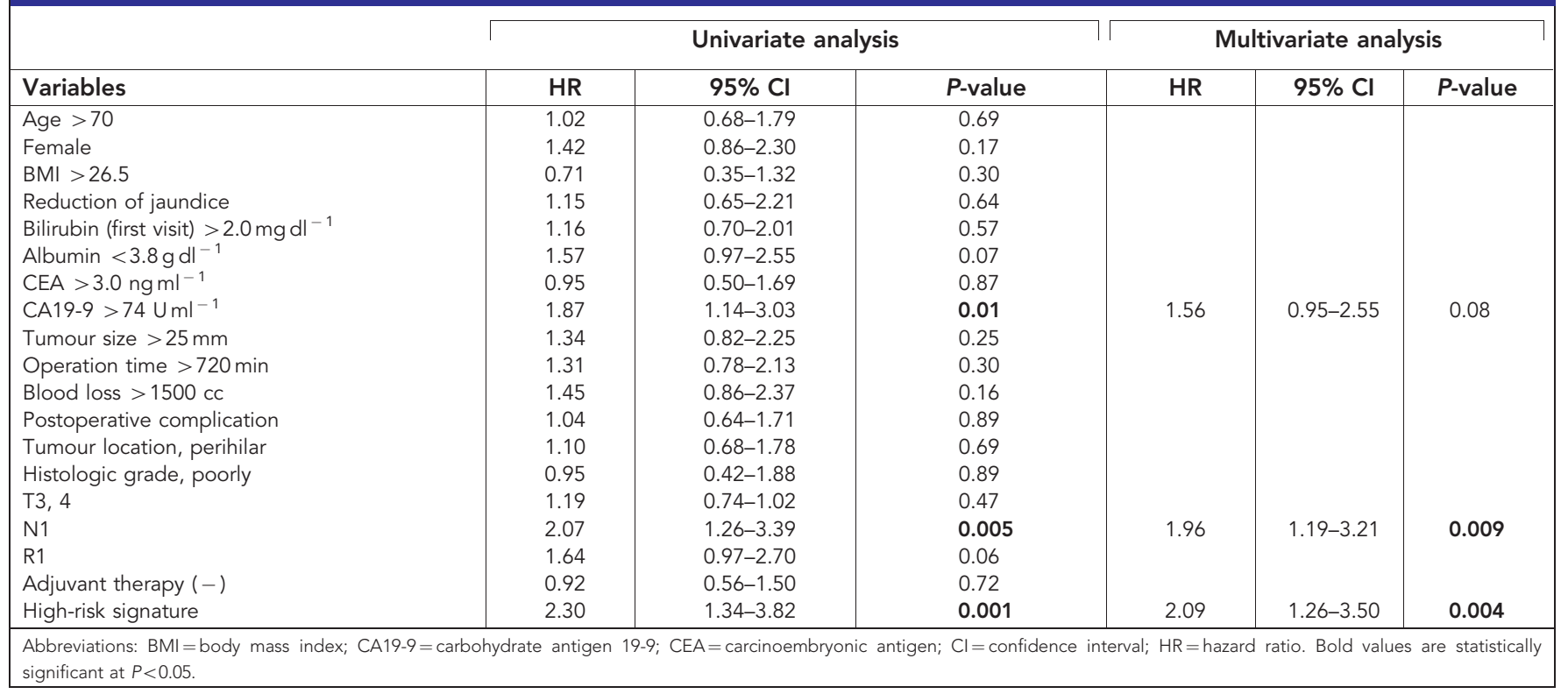

difference was marginal $(\mathrm{HR}=2.51, P=0.051$; Supplementary Figure S3).

\section{DISCUSSION}

As mentioned in hallmarks of cancer at the next generation, evading immune destruction and presence of tumour-promoting inflammation were additional hallmarks involving in the pathogenesis and progression of all cancers (Hanahan and Weinberg, 2011). We found that a high-risk signature defined by infiltration of inflammatory and immune cells was an independent predictor of poor prognosis in ECC patients with surgical resection. Although the high-risk signature was not associated with background characteristics relevant to tumour progression, it could predict disease recurrence and progression after surgery. Although the prognostic value of each cell type was substantial, we aimed to establish a predictor derived from tumour biological characteristics in the belief that multiple parameters would reduce current experimental limitations and increase the accuracy of patient classification. In the beginning, we had made a risk signature model with three types of cells (TANs, $\mathrm{CD}^{+}{ }^{+} \mathrm{T}$ cells, and Tregs) which showed the significant correlation with OS in single-cell analysis (Supplementary Figure S4a), and this model showed nice correlation with patients' prognosis (RFS: $\mathrm{HR}=1.38, P=0.15$; OS: $\mathrm{HR}=1.72, \quad P=0.03$ Supplementary Figure S4b). Interestingly, however, four-cell type model including TAMs showed better correlation with patients' prognosis than three-cell type model. We believe that TAM somehow regulates immune cell status relevant to tumour progression, although TAM by itself is not associated with prognosis. The number of TANs was significantly correlated with that of TAMs, CD8 ${ }^{+} \mathrm{T}$ cells, and Tregs, suggesting that those cells collaborate to produce inflammation affecting tumour development, and in this patient series, the regulation of inflammatory circumstances was of great importance in ECC progression and has future implications for clinical therapeutics.

Large numbers of tumour-infiltrating neutrophils (Jensen et al, 2009; Li et al, 2011; Gu et al, 2012; Coffelt et al, 2016) and macrophages (Zhu et al, 2008; Hasita et al, 2010; Steidl et al, 2010; Zhu et al, 2008) are positively associated with disease progression in many types of cancer. In clinical practice, a small number of $\mathrm{CD}^{+} \mathrm{T}$ cells (Naito et al, 1998; Zhang et al, 2003) and a large number of Tregs (Curiel et al, 2004; Hiraoka et al, 2006; Tanaka and Sakaguchi (2017)) have also been associated with tumour development. High TAN, low $\mathrm{CD}^{+} \mathrm{T}$ cell, and high Treg populations were also significantly associated with worse OS in this series of ECC patients with surgical resection. Previous studies of tumour immune cells found that TAN depletion slowed tumour growth and resulted in an increase of activated CD8 ${ }^{+}$ $\mathrm{T}$ cells (Chao et al, 2016; Coffelt et al, 2016; Fridlender et al, 2009). Tumour associated neutrophils have also been shown to 
mediate the infiltration of macrophages and Tregs by secreting CCL2 and CCL17, which resulted in enhanced HCC growth and metastasis (Mishalian et al, 2014; Zhou et al, 2016). Our finding that the numbers of TANs, TAMs, and Tregs in ECC patients were positively correlated is in line with previous results. The collective evidence suggests that TAN may be a key regulator of inflammation and immune status. Further study of the interaction of tumour-infiltrating immune cells in cholangiocarcinoma is warranted (Elinav et al, 2013; Grivennikov et al, 2010).

The clinical relevance of the risk-signature to recurrence pattern depends on recent investigations showing that tumour-induced systemic accumulation of neutrophils and macrophages acts to produce premetastatic niches and promote distant metastasis. Inflammatory cells in those niches inhibit antitumour $\mathrm{T}$-cell immunity and promote immunosuppressive cells, including Tregs (Coffelt et al, 2015, 2016; Qian and Pollard, 2010; Tuting and de Visser, 2016). As expected, high-risk signatures were correlated with postoperative distant recurrence. A high-risk signature may represent a more aggressive phenotype, which results in a higher rate of lymph node spread as well as a greater propensity to recur at a distant site. Patients with a high-risk signature may be candidates for intensified strategies. The high-risk signature should be validated prospectively and may be used to stratify patients, along with other prognostic factors (high CA19-9 value, lymph node metastasis), in further adjuvant studies.

To determine the clinical implications of high-risk signatures in addition to its prognostic value, we also carefully evaluated its impact on chemotherapeutic response. A high-risk signature was correlated with resistance to gemcitabine-based chemotherapy used after recurrence. Previous studies have suggested that inflammatory and immune cells are responsible for chemotherapy resistance or sensitivity. In HCC model, TANs, TAMs, and Tregs had the ability to promote neovascularisation and inhibit Sorafenib-induced anti-angiogenesis (Zhou et al, 2016). In ovarian cancer, $\mathrm{CD}^{+} \mathrm{T}$ cell-derived interferon $\gamma$ abrogated resistance to platinum-based chemotherapy by altering glutathione metabolism of stromal fibroblasts in the tumour microenvironment (Wang et al, 2016). Increased intratumoural levels of the proinflammatory cytokines IL- 6 and IL-8 levels have been associated with multidrug and apoptosis resistance in several cancers (He et al, 2011; Shi et al, 2012). Gemcitabine is a key drug for biliary tract cancer, and only effective drug therapy is cisplatin plus gemcitabine for locally advanced or metastatic biliary tract cancer (Valle et al, 2010). Activity of transcription factors promoting inflammation, including high mobility group A1 (HMGA1) and nuclear factor- $\kappa \mathrm{B}$ (NF$\kappa \mathrm{B})$, is associated with gemcitabine resistance in pancreatic cancer (Arlt et al, 2003; Kong et al, 2010). The genomic landscape of cholangiocarcinoma is slowly being unveiled with clinically significant results (Nakamura et al, 2015). For example, mutation-specific $\mathrm{CD}^{+}{ }^{+} \mathrm{T}$ cell could be potential therapeutic targets (Tran et al, 2014). Immunotherapy targeting tumour-specific neoepitopes encourages personalised therapy in patients with metastatic cholangiocarcinoma (Loffler et al, 2016). The roles of tumour-infiltrating inflammatory and immune cells are becoming increasingly clear, and suggest that this risk signature focusing on these cells might be used to stratify patients by tumour microenvironment status and immune cell profile.

Since we acknowledge that there are several limitations in the current study, they are major issues to be addressed in the future work. (1) The number of patients was not enough for validation of the outcome. Multicentre analysis with different cohorts would confirm the impact of risk-signature in ECC. (2) Although the current study focused on the impact of the interaction of several major immune cells involved in tumour development by statistical approach with immunohistochemistry, the underlying mechanisms by which those major immune cells interact with each other remains unclear. In situ analysis by isolating those immune cells is our next concern. (3) Risk-signature in primary tumour had a notable impact on the activity of chemotherapy on recurrent disease; however, the result is based on the concept that recurrent tumour is genetically similar to the primary tumour resected. Prognostic serological marker for risk-signature of the tumour is of great interest and under investigation.

In conclusion, tumour infiltrating inflammatory and immune cells might play a pivotal role in the ECC microenvironment. The risk signature derived from those cells had a clinical significance and independently indicated prognosis of ECC patients with curative resections.

\section{ETHICAL STANDARDS}

All procedures complied with the ethical standards of the relevant local and national committees on human experimentation and with the latest version of the Helsinki Declaration of 1964. Informed consent or acceptable substitute was obtained from all patients before study inclusion.

\section{ACKNOWLEDGEMENTS}

We thank Keisuke Miyake, Yoko Ogata and Hiroko Taniguchi for their valuable technical assistance. This work was supported in part by a Grant-in-Aid for Scientific Research from the Japan Society for the Promotion of Science (JSPS) KAKENHI (grant number 16K19936).

\section{CONFLICT OF INTEREST}

The authors declare no conflict of interest.

\section{AUTHOR CONTRIBUTIONS}

Conception and design: YKi, HO, YiY, SN and YKo; development of methodology: YKi, HO, SN, YS and YKo; acquisition of data (provided animals, acquired and managed patients, provided facilities, etc.) and analysis and interpretation of data (e.g., statistical analysis, biostatistics, computational analysis): $\mathrm{YKi}, \mathrm{HO}$ and $\mathrm{SN}$; writing, review and/or revision of the manuscript: $\mathrm{YKi}, \mathrm{HO}, \mathrm{YiY}, \mathrm{YKo}$ and $\mathrm{HB}$; administrative, technical, or material support (i.e., reporting or organising data, constructing databases): YKi, HO, YiY, SN, YS, YKo and $\mathrm{HB}$; study supervision: YiY, KM, KI, DH, YKo, AC, TI and HB.

\section{REFERENCES}

Arlt A, Gehrz A, Muerkoster S, Vorndamm J, Kruse ML, Folsch UR, Schafer H (2003) Role of NF-kappaB and Akt/PI3K in the resistance of pancreatic carcinoma cell lines against gemcitabine-induced cell death. Oncogene 22: 3243-3251.

Balkwill F, Mantovani A (2001) Inflammation and cancer: back to Virchow? Lancet 357: 539-545.

Chao T, Furth EE, Vonderheide RH (2016) CXCR2-dependent accumulation of tumor-associated neutrophils regulates T-cell immunity in pancreatic ductal adenocarcinoma. Cancer Immunol Res 4: 968-982.

Coffelt SB, Kersten K, Doornebal CW, Weiden J, Vrijland K, Hau CS, Verstegen NJ, Ciampricotti M, Hawinkels LJ, Jonkers J, de Visser KE (2015) IL-17-producing gammadelta T cells and neutrophils conspire to promote breast cancer metastasis. Nature 522: 345-348.

Coffelt SB, Wellenstein MD, de Visser KE (2016) Neutrophils in cancer: neutral no more. Nat Rev Cancer 16: 431-446.

Coussens LM, Werb Z (2002) Inflammation and cancer. Nature 420: 860-867. 
Curiel TJ, Coukos G, Zou L, Alvarez X, Cheng P, Mottram P, Evdemon-Hogan M, Conejo-Garcia JR, Zhang L, Burow M, Zhu Y, Wei S, Kryczek I, Daniel B, Gordon A, Myers L, Lackner A, Disis ML, Knutson KL, Chen L, Zou W (2004) Specific recruitment of regulatory T cells in ovarian carcinoma fosters immune privilege and predicts reduced survival. Nat Med 10: 942-949.

de Visser KE, Eichten A, Coussens LM (2006) Paradoxical roles of the immune system during cancer development. Nat Rev Cancer 6: 24-37.

Edge SB, Byrd DR, Compton C, Fritz A, Greene FL, Trotti A (2010) American Joint Committee on Cancer (AJCC). Cancer Staging Manual. 7th edn, Springer-Verlag: New York.

Elinav E, Nowarski R, Thaiss CA, Hu B, Jin C, Flavell RA (2013) Inflammation-induced cancer: crosstalk between tumours, immune cells and microorganisms. Nat Rev Cancer 13: 759-771.

Fontugne J, Augustin J, Pujals A, Compagnon P, Rousseau B, Luciani A, Tournigand C, Cherqui D, Azoulay D, Pawlotsky JM, Calderaro J (2017) PD-L1 expression in perihilar and intrahepatic cholangiocarcinoma. Oncotarget 8: 24644-24651.

Fridlender ZG, Sun J, Kim S, Kapoor V, Cheng G, Ling L, Worthen GS, Albelda SM (2009) Polarization of tumor-associated neutrophil phenotype by TGF-beta: 'N1' versus 'N2' TAN. Cancer Cell 16: 183-194.

Goeppert B, Frauenschuh L, Zucknick M, Stenzinger A, Andrulis M, Klauschen F, Joehrens K, Warth A, Renner M, Mehrabi A, Hafezi M, Thelen A, Schirmacher P, Weichert W (2013) Prognostic impact of tumour-infiltrating immune cells on biliary tract cancer. Br J Cancer 109: 2665-2674.

Grivennikov SI, Greten FR, Karin M (2010) Immunity, inflammation, and cancer. Cell 140: 883-899.

Gu FM, Gao Q, Shi GM, Zhang X, Wang J, Jiang JH, Wang XY, Shi YH, Ding ZB, Fan J, Zhou J (2012) Intratumoral IL-17(+) cells and neutrophils show strong prognostic significance in intrahepatic cholangiocarcinoma. Ann Surg Oncol 19: 2506-2514.

Hanahan D, Weinberg RA (2011) Hallmarks of cancer: the next generation. Cell 144: 646-674.

Hasita H, Komohara Y, Okabe H, Masuda T, Ohnishi K, Lei XF, Beppu T, Baba H, Takeya M (2010) Significance of alternatively activated macrophages in patients with intrahepatic cholangiocarcinoma. Cancer Sci 101: 1913-1919.

He W, Luistro L, Carvajal D, Smith M, Nevins T, Yin X, Cai J, Higgins B, Kolinsky K, Rizzo C, Packman K, Heimbrook D, Boylan JF (2011) High tumor levels of IL6 and IL8 abrogate preclinical efficacy of the gammasecretase inhibitor, RO4929097. Mol Oncol 5: 292-301.

Hiraoka N, Onozato K, Kosuge T, Hirohashi S (2006) Prevalence of FOXP3 + regulatory $\mathrm{T}$ cells increases during the progression of pancreatic ductal adenocarcinoma and its premalignant lesions. Clin Cancer Res 12: 5423-5434.

Hoshida Y, Villanueva A, Kobayashi M, Peix J, Chiang DY, Camargo A, Gupta S, Moore J, Wrobel MJ, Lerner J, Reich M, Chan JA, Glickman JN, Ikeda K, Hashimoto M, Watanabe G, Daidone MG, Roayaie S, Schwartz M, Thung S, Salvesen HB, Gabriel S, Mazzaferro V, Bruix J, Friedman SL, Kumada H, Llovet JM, Golub TR (2008) Gene expression in fixed tissues and outcome in hepatocellular carcinoma. N Engl J Med 359: 1995-2004.

Jensen HK, Donskov F, Marcussen N, Nordsmark M, Lundbeck F, von der Maase H (2009) Presence of intratumoral neutrophils is an independent prognostic factor in localized renal cell carcinoma. J Clin Oncol 27: 4709-4717.

Joyce JA, Pollard JW (2009) Microenvironmental regulation of metastasis. Nat Rev Cancer 9: 239-252.

Kobayashi A, Miwa S, Nakata T, Miyagawa S (2010) Disease recurrence patterns after R0 resection of hilar cholangiocarcinoma. Br J Surg 97: 56-64.

Komohara Y, Ohnishi K, Kuratsu J, Takeya M (2008) Possible involvement of the M2 anti-inflammatory macrophage phenotype in growth of human gliomas. J Pathol 216: 15-24.

Kong R, Sun B, Jiang H, Pan S, Chen H, Wang S, Krissansen GW, Sun X (2010) Downregulation of nuclear factor-kappaB p65 subunit by small interfering RNA synergizes with gemcitabine to inhibit the growth of pancreatic cancer. Cancer Lett 291: 90-98.

Li YW, Qiu SJ, Fan J, Zhou J, Gao Q, Xiao YS, Xu YF (2011) Intratumoral neutrophils: a poor prognostic factor for hepatocellular carcinoma following resection. J Hepatol 54: 497-505.

Loffler MW, Chandran PA, Laske K, Schroeder C, Bonzheim I, Walzer M, Hilke FJ, Trautwein N, Kowalewski DJ, Schuster H, Gunder M, Carcamo Yanez VA, Mohr C, Sturm M, Nguyen HP, Riess O, Bauer P, Nahnsen S, Nadalin S, Zieker D, Glatzle J, Thiel K, Schneiderhan-Marra N, Clasen S, Bosmuller H, Fend F, Kohlbacher O, Gouttefangeas C, Stevanovic S, Konigsrainer A, Rammensee HG (2016) Personalized peptide vaccine- induced immune response associated with long-term survival of a metastatic cholangiocarcinoma patient. J Hepatol 65: 849-855.

McAllister SS, Weinberg RA (2014) The tumour-induced systemic environment as a critical regulator of cancer progression and metastasis. Nat Cell Biol 16: 717-727.

Mishalian I, Bayuh R, Eruslanov E, Michaeli J, Levy L, Zolotarov L, Singhal S, Albelda SM, Granot Z, Fridlender ZG (2014) Neutrophils recruit regulatory T-cells into tumors via secretion of CCL17-a new mechanism of impaired antitumor immunity. Int J Cancer 135: 1178-1186.

Miyazaki M, Ohtsuka M, Miyakawa S, Nagino M, Yamamoto M, Kokudo N, Sano K, Endo I, Unno M, Chijiiwa K, Horiguchi A, Kinoshita H, Oka M, Kubota K, Sugiyama M, Uemoto S, Shimada M, Suzuki Y, Inui K, Tazuma S, Furuse J, Yanagisawa A, Nakanuma Y, Kijima H, Takada T (2015) Classification of biliary tract cancers established by the Japanese Society of Hepato-Biliary-Pancreatic Surgery: 3(rd) English edition. J Hepatobiliary Pancreat Sci 22: 181-196.

Naito Y, Saito K, Shiiba K, Ohuchi A, Saigenji K, Nagura H, Ohtani H (1998) CD8 $+\mathrm{T}$ cells infiltrated within cancer cell nests as a prognostic factor in human colorectal cancer. Cancer Res 58: 3491-3494.

Nakagawa S, Wei L, Song WM, Higashi T, Ghoshal S, Kim RS, Bian CB, Yamada S, Sun X, Venkatesh A, Goossens N, Bain G, Lauwers GY, Koh AP, El-Abtah M, Ahmad NB, Hoshida H, Erstad DJ, Gunasekaran G, Lee Y, Yu ML, Chuang WL, Dai CY, Kobayashi M, Kumada H, Beppu T, Baba H, Mahajan M, Nair VD, Lanuti M, Villanueva A, Sangiovanni A, Iavarone M, Colombo M, Llovet JM, Subramanian A, Tager AM, Friedman SL, Baumert TF, Schwarz ME, Chung RT, Tanabe KK, Zhang B, Fuchs BC, Hoshida Y, Precision Liver Cancer Prevention C (2016) Molecular liver cancer prevention in cirrhosis by organ transcriptome analysis and lysophosphatidic acid pathway inhibition. Cancer Cell 30: 879-890.

Nakamura H, Arai Y, Totoki Y, Shirota T, Elzawahry A, Kato M, Hama N, Hosoda F, Urushidate T, Ohashi S, Hiraoka N, Ojima H, Shimada K, Okusaka T, Kosuge T, Miyagawa S, Shibata T (2015) Genomic spectra of biliary tract cancer. Nat Genet 47: 1003-1010.

Nakeeb A, Pitt HA, Sohn TA, Coleman J, Abrams RA, Piantadosi S, Hruban RH, Lillemoe KD, Yeo CJ, Cameron JL (1996) Cholangiocarcinoma. A spectrum of intrahepatic, perihilar, and distal tumors. Ann Surg 224: 463-473discussion 473-465.

Okabe H, Beppu T, Ueda M, Hayashi H, Ishiko T, Masuda T, Otao R, Horlad H, Mima K, Miyake K, Iwatsuki M, Baba Y, Takamori H, Jono H, Shinriki S, Ando Y, Baba H (2012) Identification of CXCL5/ENA-78 as a factor involved in the interaction between cholangiocarcinoma cells and cancer-associated fibroblasts. Int J Cancer 131: 2234-2241.

Oshikiri T, Miyamoto M, Shichinohe T, Suzuoki M, Hiraoka K, Nakakubo Y, Shinohara T, Itoh T, Kondo S, Katoh H (2003) Prognostic value of intratumoral CD8 + T lymphocyte in extrahepatic bile duct carcinoma as essential immune response. J Surg Oncol 84: 224-228.

Plitas G, Rudensky AY (2016) Regulatory T cells: differentiation and function. Cancer Immunol Res 4: 721-725.

Qian BZ, Pollard JW (2010) Macrophage diversity enhances tumor progression and metastasis. Cell 141: 39-51.

Sabbatino F, Villani V, Yearley JH, Deshpande V, Cai L, Konstantinidis IT, Moon C, Nota S, Wang Y, Al-Sukaini A, Zhu AX, Goyal L, Ting DT, Bardeesy N, Hong TS, Fernandez-del Castillo C, Tanabe KK, Lillemoe KD, Ferrone S, Ferrone CR (2016) PD-L1 and HLA class I antigen expression and clinical course of the disease in intrahepatic cholangiocarcinoma. Clin Cancer Res 22: 470-478.

Shi Z, Yang WM, Chen LP, Yang DH, Zhou Q, Zhu J, Chen JJ, Huang RC, Chen ZS, Huang RP (2012) Enhanced chemosensitization in multidrugresistant human breast cancer cells by inhibition of IL-6 and IL-8 production. Breast Cancer Res Treat 135: 737-747.

Steidl C, Lee T, Shah SP, Farinha P, Han G, Nayar T, Delaney A, Jones SJ, Iqbal J, Weisenburger DD, Bast MA, Rosenwald A, Muller-Hermelink HK, Rimsza LM, Campo E, Delabie J, Braziel RM, Cook JR, Tubbs RR, Jaffe ES, Lenz G, Connors JM, Staudt LM, Chan WC, Gascoyne RD (2010) Tumorassociated macrophages and survival in classic Hodgkin's lymphoma. $N$ Engl J Med 362: 875-885.

Takahashi Y, Ebata T, Yokoyama Y, Igami T, Sugawara G, Mizuno T, Nimura Y, Nagino M (2015) Surgery for recurrent biliary tract cancer: a single-center experience with 74 consecutive resections. Ann Surg 262: 121-129.

Tanaka A, Sakaguchi S (2017) Regulatory T cells in cancer immunotherapy. Cell Res 27: 109-118.

Tran E, Turcotte S, Gros A, Robbins PF, Lu YC, Dudley ME, Wunderlich JR, Somerville RP, Hogan K, Hinrichs CS, Parkhurst MR, Yang JC, Rosenberg SA 
(2014) Cancer immunotherapy based on mutation-specific CD4 + T cells in a patient with epithelial cancer. Science 344: 641-645.

Tuting T, de Visser KE (2016) CANCER. How neutrophils promote metastasis. Science 352: 145-146.

Valle J, Wasan H, Palmer DH, Cunningham D, Anthoney A, Maraveyas A, Madhusudan S, Iveson T, Hughes S, Pereira SP, Roughton M, Bridgewater J, Investigators ABCT (2010) Cisplatin plus gemcitabine versus gemcitabine for biliary tract cancer. $N$ Engl J Med 362: 1273-1281.

Wang W, Kryczek I, Dostal L, Lin H, Tan L, Zhao L, Lu F, Wei S, Maj T, Peng D, He G, Vatan L, Szeliga W, Kuick R, Kotarski J, Tarkowski R, Dou Y, Rattan R, Munkarah A, Liu JR, Zou W (2016) Effector T cells abrogate stroma-mediated chemoresistance in ovarian cancer. Cell 165: 1092-1105.

Zhang L, Conejo-Garcia JR, Katsaros D, Gimotty PA, Massobrio M, Regnani G, Makrigiannakis A, Gray H, Schlienger K, Liebman MN, Rubin SC, Coukos G (2003) Intratumoral T cells, recurrence, and survival in epithelial ovarian cancer. N Engl J Med 348: 203-213.
Zhou SL, Zhou ZJ, Hu ZQ, Huang XW, Wang Z, Chen EB, Fan J, Cao Y, Dai Z, Zhou J (2016) Tumor-associated neutrophils recruit macrophages and T-regulatory cells to promote progression of hepatocellular carcinoma and resistance to Sorafenib. Gastroenterology 150: 1646-1658. el617.

Zhu XD, Zhang JB, Zhuang PY, Zhu HG, Zhang W, Xiong YQ, Wu WZ, Wang L, Tang ZY, Sun HC (2008) High expression of macrophage colonystimulating factor in peritumoral liver tissue is associated with poor survival after curative resection of hepatocellular carcinoma. J Clin Oncol 26: 2707-2716.

This work is published under the standard license to publish agreement. After 12 months the work will become freely available and the license terms will switch to a Creative Commons AttributionNonCommercial-Share Alike 4.0 Unported License.

Supplementary Information accompanies this paper on British Journal of Cancer website (http://www.nature.com/bjc) 